\title{
Randomized controlled trial of the effectiveness of an email-based alcohol intervention among university students: dismantling the assessment and feedback components
}

\author{
Preben Bendtsen ${ }^{1 *}$, Jim McCambridge ${ }^{2}$, Marcus Bendtsen $^{3}$, Nadine Karlsson $^{1}$, Per Nilsen ${ }^{1}$ \\ From International Network on Brief Interventions for Alcohol and Other Drugs (INEBRIA) Meeting 2011 \\ Boston, MA, USA. 21-23 September 2011
}

University students in Sweden routinely receive e-mailbased alcohol interventions sent from student health services. Earlier trials have examined the effectiveness of these interventions in simple parallel group designs. This exploratory study was undertaken in preparation for a larger trial. Using a dismantling design, we randomized 5227 students to either routine assessment and feedback (Group 1 ); assessment-only without feedback (Group 2); or no assessment and no feedback (Group 3). At baseline, all participants were blinded to study participation, with no contact made with Group 3. At 6-8 week follow-up, students were approached to participate in a cross-sectional alcohol study. Overall, $45 \%(\mathrm{~N}=2336)$ of those targeted for study completed follow-up. Attrition was similar in Groups 1 and 2 (approximately $41 \%$ retained) but somewhat lower in Group 3 (52\% retained). Intention-to-treat analyses among all participants, regardless of their baseline drinking status, revealed no differences between groups. Per-protocol analyses of Groups 1 and 2 among those who accepted the e-mail intervention offer (approximately 37\%) and who screened positive for risky drinking (62\% followup rate) suggested small beneficial effects on weekly consumption attributable to feedback. E-mail offer of alcohol intervention alone in an unselected population of university students was not found to be beneficial, although between-group differences in attrition prevent strong conclusions. Small benefits may follow actual uptake of e-mailed feedback intervention. The design of the main trial was positively influenced by data from this unusually large pilot study.

'Department of Medicine and Health, Linköping University, Linköping, Sweden

Full list of author information is available at the end of the article
Author details

${ }^{1}$ Department of Medicine and Health, Linköping University, Linköping, Sweden. 'London School of Hygiene \& Tropical Medicine, University of London, London, UK. ${ }^{3}$ Department of Computer and Information Science, Linköping University, Sweden.

Published: 9 October 2012

\section{doi:10.1186/1940-0640-7-S1-A91}

Cite this article as: Bendtsen et al: Randomized controlled trial of the effectiveness of an email-based alcohol intervention among university students: dismantling the assessment and feedback components. Addiction Science \& Clinical Practice 2012 7(Suppl 1):A91.

Submit your next manuscript to BioMed Central and take full advantage of:

- Convenient online submission

- Thorough peer review

- No space constraints or color figure charges

- Immediate publication on acceptance

- Inclusion in PubMed, CAS, Scopus and Google Scholar

- Research which is freely available for redistribution

\section{Biomed Central}

